OPEN ACCESS

Edited by:

Hervé Emonard,

Centre National de la Recherche Scientifique (CNRS), France

Reviewed by:

Nicholas Oberlies,

University of North Carolina at Greensboro, United States Tyler Nelson Graf

University of North Carolina at Greensboro, United States

*Correspondence: Pius S. Fasinu fasinu@campbell.edu

Specialty section:

This article was submitted to Pharmacology of Anti-Cancer Drugs,

a section of the journal

Frontiers in Oncology

Received: 24 September 2019 Accepted: 18 November 2019 Published: 03 December 2019

Citation:

Fasinu PS and Rapp GK (2019) Herbal Interaction With

Chemotherapeutic Drugs - A Focus on Clinically Significant Findings. Front. Oncol. 9:1356. doi: 10.3389/fonc.2019.01356

\section{Herbal Interaction With Chemotherapeutic Drugs-A Focus on Clinically Significant Findings}

\author{
Pius S. Fasinu* and Gloria K. Rapp
}

Department of Pharmaceutical Sciences, College of Pharmacy \& Health Sciences, Campbell University, Buies Creek, NC, United States

One of the most consequential risks associated with the concomitant use of herbal products and chemotherapeutic agents is herb-drug interactions. The risk is higher in patients with chronic conditions taking multiple medications. Herb-drug interaction is particularly undesirable in cancer management because of the precipitous dose-effect relationship and toxicity of chemotherapeutic agents. The most common mechanism of herb-drug interaction is the herbal-mediated inhibition and/or induction of drug-metabolizing enzymes (DME) and/or transport proteins leading to the alteration in the pharmacokinetic disposition of the victim drug. Most mechanistic research has focused on laboratory-based studies, determining the effects of herbal products on DMEs and extrapolating findings to predict clinical relevance; however, not all $\mathrm{DME} /$ transporter protein inhibition/induction results in clinical herb-drug interaction. This study reviews relevant literature and identified six herbal products namely echinacea, garlic, ginseng, grapefruit juice, milk thistle, and St John's wort, which have shown interactions with chemotherapeutic agents in humans. This focus on clinically significant herb-drug interaction, should be of interest to the public including practitioners, researchers, and consumers of cancer chemotherapy.

Keywords: cancer, chemotherapy, complementary and alternative medicine, drug interaction, herb-drug interaction, pharmacokinetics

\section{INTRODUCTION}

Like regular synthetic and natural drugs, phytochemicals are capable of altering physiologic processes and eliciting toxicity. Despite the scarcity of information on the safety or otherwise of herbal preparations, sales and use of medicinal herbs and complementary medicines have increased globally. In the United States, the passage of the Dietary Supplement Health and Education Act 25 years ago is believed to have further popularized herbal products and enhanced public confidence in the quality of commercial supplements. One of the major concerns in herbal supplementation is the concurrent use with prescription medicine. Based on the study conducted by Rashrash et al. (1) which relied on the data from the 2015 National Consumer Survey on the Medication Experience and Pharmacists' Roles, the practice of combining prescription medicine with herbal supplements among adults in the United States cuts across all disease states, with $38 \%$ of prescription drug users reporting concomitant use of herbal products. One of the most frequent users of herbal medicines, according to the study, are cancer patients (43.1\%) surpassed only by stroke patients (48.7\%). One study reported a $78 \%$ prevalence of herbal and supplementary medicine use among patients on 
chemotherapy, with $27 \%$ assessed to be at a risk of deleterious herb-drug interaction (2). In another recent study, more than half of the respondents reported usage of dietary supplements (which include herbal products) along with chemotherapeutic agents (3).

While the benefit of concomitant herb-drug use may be uncertain, one of the known major clinical consequences of such practice is herb-drug interactions. Not well-known until the accidental discovery of the grapefruit juicefelodipine interaction, leading to a 2.8 -fold increase in the oral bioavailability of felodipine (4), herb-drug interaction has become an important consideration in pharmacotherapy and is assuming a subcategory of research study on its own. A casual PubMed search with "herb-drug interaction" as a search term would yield no relevant result until after this grapefruitfelodipine phenomenon. Subsequently, the number of herb-drug interaction -related publications increased dramatically, remaining steady over the years (Figure 1) and leading to the introduction of herb-drug interaction as a Medical Subject Heading $(\mathrm{MeSH})$ in 2004.

Herb-drug interactions occur when the pharmacological disposition and/or effect of a drug of interest is altered by the presence of a concurrently administered herbal product. In most cases, herb-drug interactions are mild and could be inconsequential. However, in several instances, therapeutic interventions have been warranted consequent to herb-drug interaction. Such herb-drug interactions include reported bleeding induced by garlic (Allium sativum) combined with warfarin, extrapyramidal effects precipitated by betel nuts (Areca catechu) in patients taking neuroleptic drugs, and induction of mania in patients taking antidepressants along with ginseng (Panax ginseng), among several other clinically significant reported herb-drug interactions (5-7).

Chemotherapeutic agents are generally toxic with an array of side effects. Some of the principal reasons cancer patients

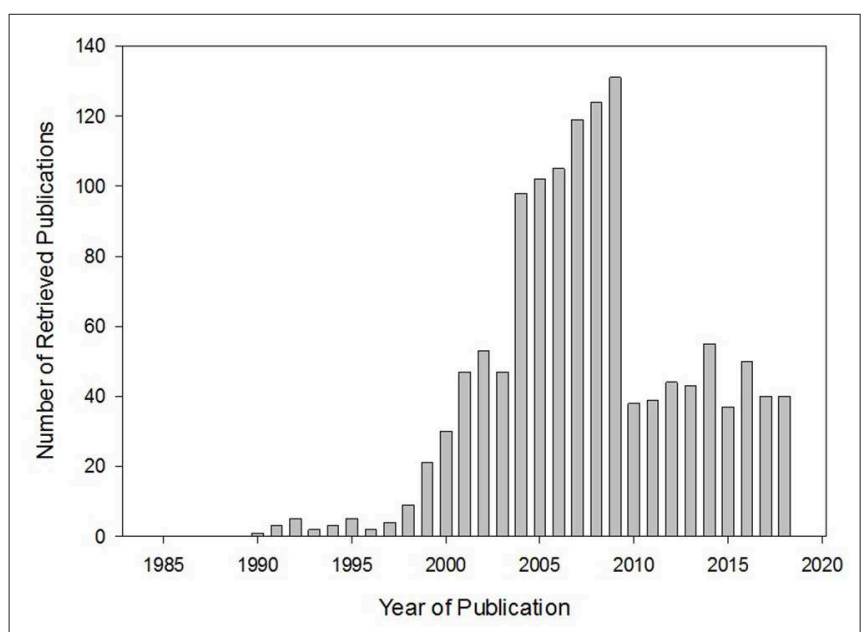

FIGURE 1 | Relevant publications retrieved from PubMed search using "herb-drug interaction" as a search term. The trend shows the introduction of and enhanced interest in herb-drug interaction. Interest has been maintained in this area over the years. combine herbal products with their anti-cancer drugs are the need to manage the side effects associated with chemotherapy and to enhance a general well-being. The potential risk of herb-drug interaction from such herbal use outweighs any benefit. There are several reasons why herb-drug interactions are undesirable in chemotherapy. First, most chemotherapeutic agents have a narrow therapeutic window, thus any alteration in this steep dose-response relationship can lead to toxic manifestations (8). Secondly, plasma concentrations of some chemotherapeutic agents have been shown to be a poor predictor of safety and efficacy (9). Reliance on PK profile in dosage designs have shown a wide inter-individual variation in responses to chemotherapy (10). This is compounded by the variations in the measurable drug concentration in the plasma and the target sites of action. It is thus plausible that slight alteration in the disposition of a chemotherapeutic agent following a delicately established effective and safe dosing will not only be counter-productive but will lead to therapy failure or toxicity. Thirdly, some chemotherapeutic agents, such as ifosfamide and cyclophosphamide, are prodrugs whose efficacy depends on effective biotransformation by cytochrome P450 (CYP) enzymes. Since most herb-drug interactions result from the inhibitory/inductive effect of phytochemicals on these metabolic enzymes, such drugs can easily be rendered ineffective or toxic by herb-drug interaction. Finally, most cancer patients have co-morbidities necessitating the use of multiple drugs, aside from antiemetic agents and other chemotherapy-associated medications. This would increase their risk of experiencing an herb-drug interaction.

Some epidemiological studies have reported that about one-tenth of all general hospital admissions might be due to the effect of multiple drug use resulting in adverse drug interactions and reactions $(11,12)$. Drug interactions alter drug concentrations in the body, which is particularly undesirable with chemotherapeutic agents that are dosed close to their maximal tolerable levels. On one hand, drug interactions resulting in increased clearance of the cytotoxic drug can lead to subtherapeutic drug exposure, enhance the development of drug resistance, and/or lead to therapy failure. On the other hand, accumulation of cytotoxic drugs resulting from drug interactions can precipitate potentially life-threatening toxicities due to supratherapeutic drug concentrations. Cancer patients often take several medications concomitantly due to co-morbidities and other cancer-associated conditions. In addition to the high risk of drug-drug interactions in such patients, the use of herbal products and the additional risk of herb-drug interaction complicate therapeutic expectations. Finally, the inherent pharmacodynamic effects of the herbal products, including organ-specific effects, and long-term interactions with physiologic receptors may not be beneficial to cancer patients.

Several herbal products have been studied in different patient groups to assess for herb-drug interaction. Clinically relevant information on herb-drug interaction in oncology is generally sparse. Most predictions are based on in vitro and preclinical animal studies; however, a few case reports and studies in humans are available to provide perspectives on the risk of herb-drug 
interactions in clinical settings. Therefore, the aim of this paper is to provide a review of the currently available literature evidence of herb-drug interaction in oncology, with emphasis on herbal products that have shown such interactions in human studies.

\section{METHODS}

This is a review conducted to provide an overview of herbal products capable of inducing clinically consequential herbdrug interaction in cancer chemotherapy. The review was systematically conducted by searching PubMed, Medline, Cochrane, Web of Knowledge, Scopus, and Google Scholar databases for original research, and case reports on herb-drug interaction using relevant search terms and the combinations thereof, including common herbal products, individual chemotherapeutic agents, "herbal interactions," and "herbdrug interactions." The reference lists of retrieved review papers/meta-analyses were also used to identify relevant publications. Inclusion was limited to publications available in English language and of studies performed in humans to evaluate interactions between herbal supplements and anti-cancer drugs. Searches were not limited by dates or place of publications.

\section{RESULTS}

A total of 345 publications were retrieved. The titles and abstracts were reviewed to determine if publications met inclusion criteria, and only 11 publications met the inclusion criteria. All of the databases searched, except Cochrane, returned the 11 clinically relevant studies. Cochrane did not have the clinical case reports. The included studies covered six herbal products-echinacea, garlic, ginseng, grapefruit juice, milk thistle, and St John's wortwhich have been investigated in humans for potential interaction with chemotherapeutic agents. A summary of these studies is provided in Table 1. Subsequent subsections discuss these results. A highlight of the applicable mechanism of herb-drug interaction in cancer chemotherapy was also extracted and discussed below.

\section{Applicable Mechanisms of Herb-Drug Interaction in Oncology}

Understanding the mechanism of herb-drug interaction can help predict potentially harmful interactions. The mechanism of herbdrug interaction can broadly be categorized as pharmaceutical, pharmacodynamic, and pharmacokinetic. Pharmaceutical interactions usually arise from physicochemical incompatibility among drugs and formulations when they come in close proximity, such as in an IV bag. Information on pharmaceutical incompatibility of the various herbal formulations with

TABLE 1 | Studies of herbal interaction with chemotherapeutic agents conducted in human subjects.

\begin{tabular}{|c|c|c|c|c|}
\hline Herbal product & $\begin{array}{l}\text { Cancer } \\
\text { drug }\end{array}$ & $\begin{array}{l}\text { Study type and } \\
\text { description }\end{array}$ & Findings & References \\
\hline Echinacea & Etoposide & Case report & $\begin{array}{l}\text { Taking echinacea with etoposide was found to significantly } \\
\text { decrease the platelet nadir }\left(16 \times 10^{3} / \mathrm{L}\right) \text { when compared to the } \\
\text { nadir of etoposide alone }\left(44 \times 10^{3} / \mathrm{L}\right)\end{array}$ & (13) \\
\hline Echinecea & Docetaxel & $\begin{array}{l}\text { Prospective study in } \\
10 \text { cancer patients }\end{array}$ & $\begin{array}{l}\text { Echinacea did not cause significant alteration in the } \\
\text { pharmacokinetics of docetaxel }\end{array}$ & $(14)$ \\
\hline Garlic & Docetaxel & $\begin{array}{l}\text { Prospective, patient } \\
\text { controlled, } \\
\text { pharmacokinetic }\end{array}$ & $\begin{array}{l}\text { Garlic was found to decrease docetaxel clearance. Although this } \\
\text { decrease was non-statistically significant, it could potentially } \\
\text { increase adverse effects due to accumulation of docetaxel }\end{array}$ & (15) \\
\hline Ginseng & Imatinib & Case report & $\begin{array}{l}\text { Patient taking imatinib for } 7 \text { years started having symptoms of } \\
\text { hepatotoxicity after beginning to consume ginseng. Hepatotoxicity } \\
\text { resolved upon discontinuation of ginseng }\end{array}$ & (16) \\
\hline Grapefruit juice & Docetaxel & Case report & $\begin{array}{l}\text { Grapefruit juice was found to increase the AUC and terminal } \\
\text { half-life of docetaxel, while decreasing clearance of docetaxel }\end{array}$ & (17) \\
\hline Grapefruit juice & Nilotinib & $\begin{array}{l}\text { Open label, } \\
\text { randomized, } 2 \text { period } \\
\text { crossover }\end{array}$ & $\begin{array}{l}\text { Grapefruit juice was found to increase the AUC and peak } \\
\text { concentration of nilotinib but did not affect the elimination half-life }\end{array}$ & (18) \\
\hline Milk thistle & Irinotecan & $\begin{array}{l}\text { Pharmacokinetic } \\
\text { study }\end{array}$ & $\begin{array}{l}\text { Milk thistle was found to cause a statistically insignificant decrease } \\
\text { in irinotecan clearance, making it unlikely to cause a clinical impact }\end{array}$ & (19) \\
\hline St John's wort & Docetaxel & $\begin{array}{l}\text { Pharmacokinetic } \\
\text { study }\end{array}$ & $\begin{array}{l}\text { St John's wort was found to cause a significant decrease in } \\
\text { plasma docetaxel concentration }\end{array}$ & (20) \\
\hline St John's wort & Irinotecan & $\begin{array}{l}\text { Unblinded, } \\
\text { randomized } \\
\text { crossover study }\end{array}$ & $\begin{array}{l}\text { St John's wort caused a decrease in plasma concentrations of } \\
\text { active metabolite (SN-38) by } 42 \%\end{array}$ & (21) \\
\hline St John's wort & Imatinib & $\begin{array}{l}\text { Open label, crossover } \\
\text { pharmacokinetic } \\
\text { study }\end{array}$ & $\begin{array}{l}\text { St John's wort decreased plasma concentration of imatinib by } \\
32 \% \text { and decreased the half-life of imatinib by } 21 \%\end{array}$ & (22) \\
\hline St John's wort & Imatinib & $\begin{array}{l}2 \text { period, open-label, } \\
\text { fixed sequence study }\end{array}$ & $\begin{array}{l}\text { St John's wort increased clearance of imatinib by } 43 \% \text {, and } \\
\text { decreased its plasma concentration by } 30 \%\end{array}$ & (23) \\
\hline
\end{tabular}


prescription drugs is generally non-existent. This type of interaction is also not very likely with herbal products because little to no contact often exist with prescription drugs before any concomitant administration. Pharmacodynamic interactions are those involving the potentiation, additive, or antagonistic effect of a drug by the presence of an herbal product. To predict this, the biomolecular and pharmacological effect of the individual herbs and their phytoconstituents must be understood. Very little is known about the identity and biological effect of the active phytochemicals in the myriad other herbs used by patients that are not discussed here. However, the potential for pharmacodynamic herb-drug interaction is always present due to the ability of phytochemicals to interact with biological receptors. For example, the antidepressant effect of St John's wort may be expected to be additive in patients taking prescription drugs for the treatment of depression.

The most important category of herb-drug interaction has been identified as pharmacokinetic. The majority of clinically significant pharmacokinetic drug interactions occurs due to the inhibition or induction of the metabolism/clearance of one drug by another (24). This is molecularly mediated by drug metabolizing enzymes and transport proteins. Most anticancer drugs are substrates of CYPs and transport proteins (Table 2). Phytochemical compounds are capable of inhibiting and/or inducing drug-metabolizing enzymes, particularly the CYPs. CYP inhibition delays the clearance of CYP substrates, leading to drug accumulation. This is undesirable in cancer chemotherapy due to the narrow therapeutic window of many anti-cancer drugs. CYP inhibition is also deleterious for CYPdependent prodrugs like ifosfamide and cyclophosphamide, whose biotransformation, once stalled, can lead to therapy failure. The induction of CYP enzymes lead to increased metabolic activity and reduced drug exposures. The resultant sub-therapeutic exposure can lead to treatment failure in the short term, and drug resistance in the long term. Enzyme inhibition/induction affect both the bioavailability and clearance of cancer drugs. Several herbal products including St John's wort, ginkgo, ginseng, licorice, kava, garlic, cranberry, grape seed, germander, goldenseal, valerian, and black cohosh, among others have been shown to inhibit or induce CYPs $(24,25)$. Similar inhibitory and inductive effects of herbal products on phase II enzymes have been variously reported (26-29). There can also be inhibition/induction of renal excretion and alteration of tissue distribution through displacement from protein binding.

Pharmacokinetic herb-drug interactions are also mediated by herbal interaction with transport proteins, principal among which is P-glycoprotein (P-gp). P-gp, also referred to as the multidrug resistance protein 1 (MDR1), or ATP-binding cassette sub-family B member 1 (ABCB1), is a $160-\mathrm{kD}$ ATP-dependent efflux surface glycoprotein first identified in Chinese hamster ovary cells (30). P-gp is localized in various tumors expressing the

TABLE 2 | Several anti-cancer drugs are substrates of drug-metabolizing enzymes and transport proteins.

\begin{tabular}{|c|c|}
\hline $\begin{array}{l}\text { Metabolizing } \\
\text { enzyme/transporter }\end{array}$ & Anti-cancer substrates \\
\hline CYP1A1/1A2 & Axitinib, bendamustine, bortezomib, dacarbazine, etoposide, exemestane, flutamide, pazopanib, pomalidomide, tegafur \\
\hline CYP2A6 & Cyclophosphamide, ifosfamide, letrozole, tegafur \\
\hline CYP2B6 & Busulfan, cyclophosphamide, docetaxel, doxorubicin, ifosfamide, procarbazine, thiotepa \\
\hline CYP2C8 & Anastrozole, dabrafenib, cyclophosphamide, enzalutamide, ifosfamide, imatinib, lapatinib, nilotinib, paclitaxel, pazopanib, tegafur \\
\hline CYP2C9 & Busulfan, ifosfamide, idarubicin, ruxolitinib, tamoxifen \\
\hline CYP2C19 & Axitinib, bortezomib, cyclophosphamide, ifosfamide, lapatinib, pomalidomide, tamoxifen, thalidomide \\
\hline CYP2D6 & Brentuximab, doxorubicin, gefetinib, idarubicin, pomalidomide, tamoxifen, vinblastine, vinorelbine \\
\hline CYP2E1 & Dacarbazine, etoposide, cisplatin, vinorelbine \\
\hline CYP3A4/3A5 & $\begin{array}{l}\text { Anastrozole, axitinib, bortezomib, bositinib, brentuximab, cabazitaxel, cisplatin, crizotinib, cyclophosphamide, dabrafenib, dasatinib, docetaxe } \\
\text { doxorubicin, enzalutamide, etoposide, exemestane, gefetinib, imatinib, fulvestrant, ifosfamide, irinotecan, lapatinib, letrozole, mitoxantrone, } \\
\text { nilotinib, olaparib, paclitaxel, pazopanib, pomalidomide, ponatinib, procarbazine, regorafenib, ruxolitinib, sorafenib, sunitinib, temsirolimus, } \\
\text { teniposide, thiotepa, topotecan, trabectedin, vandetanib, vemurafenib, vinblastine, vincristine, vinorelbine }\end{array}$ \\
\hline GSTS & $\begin{array}{l}\text { Busulfan, carboplatin, chlorambucil, cisplatin, cyclophosphamide, dactinomycin, daunorubicin, doxorubicin, etoposide, idarubicin, ifosfamide } \\
\text { mitomycin, mitoxantrone, oxaliplatin, tamoxifen, vinblastine, vincristine, vinorelbine }\end{array}$ \\
\hline UGTS & $\begin{array}{l}\text { Anastrozole, axitinib, bicalutamide, doxorubicin, epirubicin, etoposide, exemestane, irinotecan, sorafenib, regorafenib, tamoxifen, teniposide, } \\
\text { topotecan }\end{array}$ \\
\hline $\begin{array}{l}\text { P-glycoprotein } \\
\text { (ABCB-1, MDR-1) }\end{array}$ & $\begin{array}{l}\text { Axitinib, bicalutamide, bosutinib, cytarabine, dactinomycin, dasatinib, daunorubicin, docetaxel, doxorubicin, epirubicin, etoposide, gefetinib, } \\
\text { idarubicin, imatinib, irinotecan, methotrexate, mitoxantrone, paclitaxel, sunitinib, vincristine }\end{array}$ \\
\hline MRP-1 (ABCC-1) & $\begin{array}{l}\text { Chlorambucil, daunorubicin, doxorubicin, epirubicin, etoposide, idarubicin, irinotecan, melphalan, methotrexate, mitoxantrone, tenoposide, } \\
\text { topotecan, vinblastine, vincristine }\end{array}$ \\
\hline MRP-2 (ABCC-2) & Methotrexate, sulfinpyrazone, vinblastine \\
\hline $\begin{array}{l}\text { BCRP (ABCG-2, } \\
M \times R)\end{array}$ & $\begin{array}{l}\text { Bicalutamide, dasatinib, docetaxel, daunorubicin, doxorubicin, epirubicin, gefetinib, idarubicin, imatinib, irinotecan, mitoxantrone, nilotinib, } \\
\text { paclitaxel, sorafenib, sunitinib, topotecan }\end{array}$ \\
\hline
\end{tabular}

ABC, ATP-binding cassette; BCRP, breast cancer resistant protein; MDR, multidrug resistance gene; MRP, multidrug resistance-associated protein; MXR, mitoxantrone resistanceassociated protein. 
MDR phenotype. In normal cells, $\mathrm{P}$-gp is expressed in the apical or luminal membranes of cells with excretory or barrier functions including the liver, kidney, intestines, and adrenal glands. Pgp is also a principal constituent of the physiologic bloodbrain, blood-testes, and blood-ovary barriers. These anatomical and physiological positions of P-gp enhances its protective and detoxifying functions. In relation to drugs and other xenobiotics, the efflux activity of $\mathrm{P}$-gp reduces cellular penetration and tissue distribution.

As a high-capacity transport protein, the activity of P-gp affects a wide range of structurally unrelated and pharmacologically diverse drugs, including chemotherapeutic agents, anti-retroviral drugs, immunosuppressants, cardio-active drugs, centrally-acting drugs, and several others. Numerous other drugs inhibit the activity of P-gp. Notable among these are verapamil and cyclosporine, used as standard controls in P-gp studies. Many other drugs, including ketoconazole, quinidine, ritonavir, etc., have caused adverse drug interactions through their inhibitory activity on P-gp. Herbal products and phytochemicals including silymarin and extracts from milk thistle, ginseng-derived ginsenosides, piperine, capsaicin, and several others have been reported to inhibit the activity of P-gp. Both the expression and activity of P-gp, like CYPs, can be induced (31-34). St John's wort is an example of a typical herbal P-gp inducer.

\section{Herbal Products That Have Shown Clinical Interactions With Chemotherapeutic Drugs} Echinacea

Formulations of echinacea are globally popular for complementary treatment of respiratory infections and common cold. Among cancer patients, echinacea is popular as an immunomodulatory supplement $(35,36)$. Recent studies in animals have suggested that echinacea may have beneficial effect in abating some forms of cancer, like leukemia (37). The active constituents and the pharmacological mechanism of any beneficial effect is poorly understood. Echinacea is ranked one of the top widely sold herbal preparations in the United States (38). Most of the preparations of echinacea in the United States are made from one out of the nine common species-Echinacea purpurea. Several pre-clinical studies have suggested herb-drug interaction between echinacea and anti-cancer drugs. For example, extracts of echinacea induce P-gp and CYP3A4, two major enzyme/transporter combination that play major roles in the biotransformation and pharmacokinetics of anticancer drugs [Table 1; (39)]. Echinacea is also an inhibitor of CYP3A4 (40). This dual ability to inhibit and induce drug-metabolizing enzymes makes it difficult to predict clinically significant herbdrug interaction with the various CYP/P-gp drug substrates. In human studies, echinacea caused significant increase (34\%) in the systemic clearance of midazolam, a CYP3A4 substrate (41). Therefore, there is a potential for herb-drug interaction between echinacea and anti-cancer drugs.

While preclinical studies have shown strong evidence of echinacea interacting with CYP and transport proteins, there is insufficient clinical data on herb-drug interaction with anticancer drugs. In a study in 10 cancer patients, echinacea did not cause significant alterations in the pharmacokinetics of docetaxel, which is a substrate of CYP3A4 and P-gp (14). The patients received an intravenous dose of docetaxel on day 1 , and were then treated with echinacea supplementation (20 oral drops three times daily of a commercially available product) on days 7-21. They were then administered with another dose of docetaxel on day 22. No significant changes were observed in the pharmacokinetics of docetaxel with or without echinacea supplementation. However, with darunavir, an antiretroviral drug, echinacea caused a general decrease in concentration in the HIV/AIDS patient participants (42).

In a case report, echinacea caused a significant interaction in a cancer patient taking etoposide (13). The adult patient, who was newly diagnosed with squamous cell carcinoma of the lung received cisplatin and etoposide on the first day of treatment with a recorded normal bloodwork. However, by day 8 of this first cycle chemotherapy, his platelet count had dropped by over two-thirds, necessitating platelet transfusion. The discontinuation of echinacea in the cycle 2 chemotherapy helped the patient avoid any further need for platelet transfusion. No further incidence was reported until discharge after 20 days in the hospital. Patient was instructed to avoid taking any more herbal supplements. Etoposide, a cytotoxic agent, is a CYP substrate, whose dose-limiting toxicity is myelosuppression. This interaction is understood to have been as a result of echinaceainduced CYP inhibition, leading to etoposide accumulation and the resultant thrombocytopenia.

\section{Garlic}

Garlic (Allium sativum) is one of the most popular herbal products used to supplement the treatment of infection, diabetes, and heart diseases (43). Its use is common among people with chronic diseases, such as cancer. The major bioactive component of garlic is allicin (diallyl thiosulfinate). Whole garlic extracts have been shown to inhibit the CYP3A4-dependent formation of $6 \beta$-hydroxytestosterone from testosterone through in vitro liver microsomal incubations (44).

In a study to assess the effect of garlic supplementation on the pharmacokinetics of docetaxel, Cox and co-workers administered docetaxel to women with metastatic breast cancer weekly for 3-4 weeks. A 12-day supplementation with twicedaily $600 \mathrm{mg}$ garlic was commenced on the participants 3 days after the initial dose of docetaxel (15). By Day 15 of the study, garlic supplementation reduced the clearance of docetaxel by $36 \%$ (from 30.8 to $20.0 \mathrm{~L} / \mathrm{h} / \mathrm{m}^{2}$. Although, changes in the other pharmacokinetic parameters were reported to be insignificant, the decrease in docetaxel clearance in the presence of garlic may pose significant risk of toxicity due to docetaxel accumulation. This interaction is also consistent with the ability of the phytochemicals in garlic to inhibit CYP enzymes, which are responsible for the metabolism of docetaxel.

\section{Ginseng}

Ginseng is one of the most popular herbal products sold globally and especially in the United States. Commercial 
ginseng products are made mainly from three of the several species of ginseng-Panax ginseng (Asian ginseng), Panax quinquefolius (American ginseng), and Panax japonicus (Japanese ginseng). Most therapeutic claims including energy boosting, immunomodulation, enhancement of sexual desire, and pain management are anecdotal. Pharmacological activity of ginseng is generally attributed to ginsenosides, a group of steroidal saponins, which forms the primary phytochemical constituents. Anti-oxidant and cardiovascular protective effect of ginseng have been reported $(45,46)$. Other reported pharmacological activity of ginseng include immunomodulatory and anticarcinogenic effects, neurotransmitter modulation, and antimitogenic activity (47-49).

There have been mixed findings on the effect of ginseng on drug-metabolizing enzymes and P-gp. In in vitro studies, some studies reported no inhibitory activity on CYPs, contrary to others which found inhibitory activity against DMEs (50-54). In a study involving eight healthy volunteers, the effect of the extracts of $P$. ginseng on the pharmacokinetics of midazolam and fexofenadine-substrates of CYP3A4 and P-gp, respectively, was evaluated. Results showed a significant reduction in the AUC and $\mathrm{C}_{\max }$ of midazolam, which the authors attributed to the inductive effect of ginseng on CYP3A4/5 (55).

As a popular herbal supplement among cancer patients, ginseng has the potential to mediate clinically significant interactions with chemotherapeutic agents. In a case report, an onset of imatinib-induced hepatoxicity was reported in a patient who was being treated with imatinib for chronic myelogenous leukemia (CML). Having used imatinib for 7 years, the patient developed liver dysfunction (confirmed by abnormal liver function test results showing elevated alanine aminotransferase, aspartate aminotransferase, alkaline phosphatase, total bilirubin, and albumin; as well as liver biopsy) only after concurrent use with a $P$. ginseng-containing energy drink for 3 months (16). The symptoms of hepatotoxicity were resolved after the discontinuation of the energy drink. At high blood levels, and in some patients, imatinib may induce hepatotoxicity within the first 2 years of therapy. Thus, the patient was believed to tolerate the drug before consuming the energy drink, having used it for 7 years; however, the multicomponent nature of the energy drink raises questions on the singularity of responsibility of ginseng.

\section{Grapefruit Juice}

Grapefruit (Citrus paradisi) is not a regular herbal supplement used for medicinal purposes. As a drink, it has been wellreported to influence the pharmacokinetics of a variety of drugs when consumed together. Phytochemical constituents of grapefruit juice are potent inhibitors of CYPs and P-gp. Various comprehensive reviews have been published on the interaction between grapefruit juice (GFJ) and prescription drugs $(56,57)$.

In a study in 21 healthy human volunteers, concomitant intake of grapefruit juice and nilotinib caused a $60 \%$ increase in the peak concentration of nilotinib, along with a $29 \%$ increase in the AUC (18). Participants received $400 \mathrm{mg}$ nilotinib with either $250 \mathrm{~mL}$ double strength GFJ or water in a cross-over study of two periods separated by 10 -day washout period. This was attributed to the inhibitory actions of the phytochemical constituents of grapefruit juice on CYPs.

In a case report published by Valenzuela et al., a patient diagnosed with esophageal squamous cell carcinoma, had taken $250 \mathrm{~mL}$ of GFJ daily for more than 3 months while on docetaxel and had shown unusual pharmacokinetics of docetaxel relative to dose (17). The elimination of docetaxel had been observed to be slow in the patient, with an estimated plasma clearance of $13.2 \mathrm{~L} / \mathrm{h}$ compared to the typical plasma clearance of docetaxel of $36.7 \mathrm{~L} / \mathrm{h}$. After reviewing the patient's medication records, the authors reported suspecting that GFJ might be influencing the pharmacokinetics of docetaxel in the patient. A $60 \%$ reduction in the AUC (to infinity), with a $36 \%$ increase in plasma clearance and a $10 \%$ decrease in the terminal half-life of docetaxel were observed following GFJ discontinuation. This further confirmed that GFJ suppressed the clearance of docetaxel, most likely through inhibitory activity of CYP enzymes which are responsible for the metabolism of docetaxel.

\section{Milk Thistle}

Milk thistle (Silybum marianum) is another popular herbal product used as complementary medicine in cancer patients and to boost immunity in HIV/AIDS patients. It is also used for the treatment and prevention of liver diseases. Silymarin, a mixture of biologically active flavonolignans, is the active constituent of milk thistle and generally expressed in the leaves, seeds, and fruit of the plant. Commercially available products of Milk thistle are usually provided as silymarin, a complex mixture of flavonolignans and a flavonoid. A fraction of this mixture called silibinin (containing silybin A and silybin B) have also been made commercially available. A recent publication provides a comprehensive review of these phytochemical components of Milk thistle, and their nomenclature (58). Silymarin has been clinically investigated for its anticancer activity with promising results $(59,60)$. Silymarin has been shown through in vitro studies to inhibit the activity of CYP and phase 2 enzymes $(61,62)$. This potential for herb-drug interaction has been shown in clinical studies, where silymarin significantly reduced the CYP2C9-mediated metabolism of losartan (63).

Due to the preponderance of use of milk thistle product among cancer patients, the potential for herb-drug interaction is a major clinical concern; however, clinical data on this is sparse. A study was conducted to determine if the inhibitory activity of milk thistle extract on CYP3A4 will translate to the alteration of the pharmacokinetics of irinotecan, a CYP3A4 substrate, in humans when taken together. The study in six cancer patients who were being treated with once-a-week irinotecan, in the course of which thrice-daily milk thistle was administered for 12 days assessed the pharmacokinetics of irinotecan and its metabolites. Authors reported that neither the short-term (4 days) nor prolonged use of milk thistle (12 days) resulted in any significant alteration in the pharmacokinetics of irinotecan. Only a slight and insignificant drop in clearance was observed with 31.2, 25.4, and $25.6 \mathrm{~L} / \mathrm{h}$ in the first, second and third week, respectively, reported (19). According to the authors, potential for clinically significant interaction between silymarin and CYP3A4 substrate may not be very strong because the $\mathrm{C}_{\max }$ 
of silibinin, at the usual dose, is reported to range from 0.0249 to $0.257 \mu \mathrm{M}$, a concentration that may be too low for CYP/P-gp inhibition (64).

This notwithstanding, in the absence of further proof, the risk of clinically significant herb-drug interaction between milk thistle and chemotherapeutic agents may still be present due to variations in silymarin concentrations in different commercially available milk thistle formulations.

\section{St John's Wort}

St John's wort (Hypericum perforatum) is a common herbal supplement widely used for the treatment of depression, anxiety, sleep disorders, and nervousness (65). Official guidelines in multiple countries have recommended St John's wort for the treatment of depression, which has increased the popularity and consumption of St John's wort among various patient groups (66). Other popular uses of St John's wort include in the treatment of premenstrual syndrome, alcohol withdrawal, and somatoform disorders (67-70). Several active phytochemical constituents including naphthodianthrones (like hypericin), phloroglucinols (like hyperforin), and flavonol glycoside (like hyperosides) have been isolated and characterized from St John's wort (71). The antidepressant activity of St John's wort has been attributed to hyperforin, the constituent with the most potent ability to inhibit the synaptic reuptake of central neurotransmitters such as dopamine, noradrenaline, and serotonin.

Several in vitro studies have demonstrated the ability of the extracts of St John's wort to modulate the activity of CYP and major drug transporters. For example, St John's wort has been shown as a potent inducer of CYP2B6, CYP2C19, CYP2E1, and CYP3A4. Hyperforin, in addition to its inductive effects on several CYP isoforms, is a potent inhibitor of CYP2C9 and CYP2D6. Other constituents of St John's wort have shown inhibitory activities against CYPs. For example, biapigenin, a flavonoid from St John's wort, is a potent inhibitor of CYP1A2, CYP2C9, and CYP3A4 whereas hypericin is a competitive inhibitor of CYP2C9, CYP2D6, and CYP3A4 (72). Mechanistic studies in cell lines and in animal models have demonstrated the herb-drug interaction potential of St John's wort. The effect of concomitant administration of St John's wort and several clinically important substrates of these CYPs and transporters have been investigated in humans. In some instances, clinical case reports have been published showing significant herb-drug interaction between St John's wort and prescription medicine.

In human studies and clinical case reports, St John's wort has been shown to alter the pharmacokinetics of various substrates of CYP3A4 and P-gp including omeprazole, simvastatin, cyclosporine, indinavir, verapamil, and tacrolimus (73-78).

Four clinically relevant studies retrieved from the literature, show the influence of concomitantly administered St John's wort on the pharmacokinetics of anti-cancer drugs. The influence of St John's wort on the pharmacokinetics of docetaxel, a CYP3A4 substrate, was evaluated in 10 cancer patients. Subjects were intravenously administered with $135 \mathrm{mg}$ docetaxel on day 1 of the study followed by blood withdrawal and pharmacokinetic analysis. From day 7 to 21, participants were treated with commercially available $300 \mathrm{mg}$ tablets of St John's wort extracts (Hyperiplant ${ }^{\circledR}$ ), three-times-daily. The mean AUC $\infty$ of docetaxel was decreased by $12 \%$, and the total clearance increased by $14 \%$ due to the pre-supplementation with St John's wort. In addition, the $\mathrm{C}_{\max }$ and $\mathrm{T}_{1 / 2}$ of docetaxel was decreased, non-significantly. The study also found a lower incidence of docetaxel-related adverse effects due to St John's wort supplementation (20). These observations are consistent with the mechanistic ability of St John's wort to induce CYP3A4 and accelerate the metabolism of its substrates.

In another study, the effect of St John's wort on the metabolism of irinotecan was assessed. Five cancer patients recruited for the study were treated with irinotecan with or without St John's wort supplementation for 18 days in an unblinded randomized cross-over study. St John's wort decreased the plasma level of the active metabolite, $\mathrm{SN}-38$, by $42 \%$ (21). Authors also reported a mean decrease in leucocyte counts of $63 \%$ when irinotecan alone was used compared to a $4.3 \%$ decrease count when combined with St John's wort. The reduced incidence of myelosuppression was attributed to increased metabolism of irinotecan, brought about by the inductive effects of St John's wort on the metabolism of irinotecan and SN-38. The St John's wort -irinotecan combination has also been reported to mitigate against hematologic and gastrointestinal toxicities associated with irinotecan (79).

Smith and co-workers conducted an open-label crossover study to determine the influence of St John's wort on the pharmacokinetics (PK) of imatinib in 10 healthy adult subjects (22). PK parameters were compared following a single administration of $400 \mathrm{mg}$ imatinib before and after a 2-week St John's wort treatment. St John's wort reduced the median AUC of imatinib by $32 \%$, and the observed $C_{\max }$ by $29 \%$. This significant St John's wort -induced reduction in imatinib exposure, alongside decreased plasma half-life, occurred in all 10 participants. Additionally, the $\mathrm{C}_{\max }$ in the presence of St John's wort was diminished in all participants but one.

In a similar study, using a 2-period design for an openlabel, fixed-sequence study in 12 healthy volunteers, Frye and co-workers reported a $43 \%$ increased clearance of imatinib with a $30 \%$ reduction in imatinib exposure (23). Each of the volunteers had received $400 \mathrm{mg}$ of imatinib orally on days 1 and 15, while also receiving three-times-daily $300 \mathrm{mg}$ of St John's wort from days 4 to 17. Plasma imatinib were analyzed over $72 \mathrm{~h}$ after each imatinib administration. In addition to the increased total clearance and the reduced total exposure, St John's wort caused a $31 \%$ decrease in the plasma half-life (from 12.8 to $9 \mathrm{~h}$ ) and a $20 \%$ decrease in the plasma $\mathrm{C}_{\max }$ of imatinib in the subjects. All the pharmacokinetic changes were observed in all 12 participants. These effects are significant and may pose a risk for therapeutic failure in cancer patients who take St John's wort along with their therapeutic agents.

\section{DISCUSSION}

Despite the scarcity of data on therapeutic benefit of herbal supplements in cancer, the use of herbal products is very common among cancer patients. Studies have reported figures as high as 
$50-66 \%$ use of one or more complementary/alternative medicine, the majority of which are herbal preparations, concurrently with conventional cancer therapy $(80,81)$. This review identified six herbal products-echinacea, garlic, ginseng, grapefruit juice, milk thistle, and St John's wort-which have shown clinically relevant interactions with specific chemotherapeutic agent. Several other herbal products are commonly used among cancer patients for which there are currently no clinically relevant herb-drug interaction data, but with strong potential for interactions based on laboratory-based results. These include green tea (Camellia sinensis), mistletoe (Viscum album), evening primrose (Oenothera paradoxa), parsley (Petroselinum crispum), goldenseal (Hydrastis canadensis), kava (Piper methysticum), aloe vera (Aloe barbadensis), wild yam (Dioscorea villosa), valerian (Valeriana officinalis), golden root (Rhodiola rosea), medicinal mushrooms (including species of Ganoderma, Grifola, and Trametes), agaricus (Agaricus campestris), and rooibos (Aspalathus linearis) (82).

As highlighted earlier, herb-drug combination is particularly undesirable in cancer patients because of herb-drug interaction risks. Most herb-drug interactions are pharmacokinetic in mechanism and are brought about by either the induction or inhibition of drug-metabolizing enzymes and transport proteins. Since echinacea can inhibit and induce CYP enzymes, it is difficult to predict what effect it will have on a patient's therapy. Current data is sparse and showed conflicting outcomes as to enhancing or decreasing the effect of chemotherapy. Ginseng is another inducer that may place a patient at higher risk for adverse effects if taken along with chemotherapy. Based on the case study found, it is unclear if ginseng was the definite cause of hepatotoxicity; however, since there is evidence to suggest that ginseng induces CYP enzymes, the patient's hepatotoxicity is thought to be due to the ginseng component of the energy drink. Further studies and reports are needed to assess the interaction between ginseng and chemotherapeutic agents. By inhibiting CYP enzymes, garlic and milk thistle can effectively inhibit the metabolism of certain chemotherapeutic agents. Based on the available literature, both can clinically influence the pharmacokinetics of chemotherapeutic drugs. Interaction of grapefruit juice is unique in that most people consume grapefruit juice for non-medicinal purposes. Current literature shows that grapefruit juice caused the accumulation of CYP/Pgp substrates due to inhibition, placing patients at increased

\section{REFERENCES}

1. Rashrash M, Schommer JC, Brown LM. Prevalence and predictors of herbal medicine use among adults in the United States. J Patient Exp. (2017) 4:108-13. doi: 10.1177/2374373517 706612

2. McCune JS, Hatfield AJ, Blackburn AA, Leith PO, Livingston RB, Ellis GK. Potential of chemotherapy-herb interactions in adult cancer patients. Support Care Cancer. (2004) 12:454-62. doi: 10.1007/s00520-004-0598-1

3. Luo Q, Asher GN. Use of dietary supplements at a comprehensive cancer center. J Altern Complement Med. (2018) 24:981-7. doi: $10.1089 / \mathrm{acm} .2018 .0183$ risk for adverse effects from chemotherapy. This interaction is important because it highlights the importance of diet during chemotherapy treatment.

To ensure effective care, providers should have open conversations with their patients in order to document their herb-drug use and provide necessary counseling. Patients need education on the potential beneficial and harmful effects of herbal products in cancer. Such education should include the lack of sufficient supportive data and the liberal marketing strategies employed in the sale of herbal products. Importantly, patients should understand the potential for herb-drug interaction and the attendant toxicity or therapy failure.

\section{CONCLUSION}

While the beneficial effects of the commonly consumed herbal products by cancer patients is uncertain, data from human studies suggest that some of these supplements are capable of interacting with chemotherapeutic agents. It is therefore prudent and advisable to avoid the concomitant use of anti-cancer drugs and herbal products, especially echinacea, garlic, ginseng, grapefruit juice, milk thistle, and St John's wort. Clinicians and practitioners need to be vigilant in monitoring for any herbanticancer combination.

\section{AUTHOR CONTRIBUTIONS}

PF and GR conceptualized the research, contributed equally to the literature search, synthesis, writing of the manuscript, and agree on the final version of the manuscript.

\section{FUNDING}

This research was supported by a departmental grant from the Department of Pharmaceutical Sciences, College of Pharmacy and Health Sciences, Campbell University.

\section{ACKNOWLEDGMENTS}

We would like to thank our colleagues at the Department of Pharmaceutical Sciences, College of Pharmacy and Health Sciences, Campbell University.
4. Bailey DG, Spence JD, Munoz C, Arnold JM. Interaction of citrus juices with felodipine and nifedipine. Lancet. (1991) 337:268-9. doi: 10.1016/0140-6736(91)90872-M

5. Burnham BE. Garlic as a possible risk for postoperative bleeding. Plast Reconstr Surg. (1995) 95:213. doi: 10.1097/00006534-199501000-00060

6. Huang Z, Xiao B, Wang X, Li Y, Deng H. Betel nut indulgence as a cause of epilepsy. Seizure. (2003) 12:406-8. doi: 10.1016/S1059-1311(02)00377-1

7. Engelberg D, McCutcheon A, Wiseman S. A case of ginsenginduced mania. J Clin Psychopharmacol. (2001) 21:535-7. doi: 10.1097/00004714-200110000-00015

8. Alnaim L. Therapeutic drug monitoring of cancer chemotherapy. J Oncol Pharm Pract. (2007) 13:207-21. doi: 10.1177/1078155207081133 
9. Gieschke R, Burger HU, Reigner B, Blesch KS, Steimer JL. Population pharmacokinetics and concentration-effect relationships of capecitabine metabolites in colorectal cancer patients. Br J Clin Pharmacol. (2003) 55:25263. doi: 10.1046/j.1365-2125.2003.01765.x

10. Phan VH, Moore MM, McLachlan AJ, Piquette-Miller $\mathrm{M}$, Xu $\mathrm{H}$, Clarke SJ. Ethnic differences in drug metabolism and toxicity from chemotherapy. Expert Opin Drug Metab Toxicol. (2009) 5:243-57. doi: 10.1517/17425250902800153

11. Fattinger K, Roos M, Vergeres P, Holenstein C, Kind B, Masche U, et al. Epidemiology of drug exposure and adverse drug reactions in two Swiss departments of internal medicine. Br J Clin Pharmacol. (2000) 499:158-67. doi: 10.1046/j.1365-2125.2000.00132.x

12. Zoppi M, Braunschweig S, Kuenzi UP, Maibach R, Hoigné R. Incidence of lethal adverse drug reactions in the comprehensive hospital drug monitoring, a 20-year survey, 1974-1993, based on the data of Berne/St Gallen. Eur J Clin Pharmacol. (2000) 56:427-30. doi: 10.1007/s002280000158

13. Bossaer JB, Odle BL. Probable etoposide interaction with Echinacea. J Diet Suppl. (2012) 9:90-5. doi: 10.3109/19390211.2012.682643

14. Goey AK, Meijerman I, Rosing H, Burgers JA, Mergui-Roelvink M, Keessen $\mathrm{M}$, et al. The effect of Echinacea purpurea on the pharmacokinetics of docetaxel. Br J Clin Pharmacol. (2013) 76:467-74. doi: 10.1111/bcp.12159

15. Cox MC, Low J, Lee J, Walshe J, Denduluri N, Berman A, et al. Influence of garlic (Allium sativum) on the pharmacokinetics of docetaxel. Clin Cancer Res. (2006) 12:4636-40. doi: 10.1158/1078-0432.CCR-06-0388

16. Bilgi N, Bell K, Ananthakrishnan AN, Atallah E. Imatinib and Panax ginseng: a potential interaction resulting in liver toxicity. Ann Pharmacother. (2010) 44:926-8. doi: 10.1345/aph.1M715

17. Valenzuela B, Rebollo J, Pérez $\mathrm{T}$, Brugarolas A, Pérez-Ruixo JJ. Effect of grapefruit juice on the pharmacokinetics of docetaxel in cancer patients: a case report. Br J Clin Pharmacol. (2011) 72:978. doi: $10.1111 / j .1365-2125.2011 .04052 . x$

18. Yin OQ, Gallagher N, Li A, Zhou W, Harrell R, Schran H. Effect of grapefruit juice on the pharmacokinetics of nilotinib in healthy participants. J Clin Pharmacol. (2010) 50:188-94. doi: 10.1177/0091270009336137

19. Van Erp NP, Baker SD, Zhao M, Rudek MA, Guchelaar HJ, Nortier JW, et al. Effect of milk thistle (Silybum marianum) on the pharmacokinetics of irinotecan. Clin Cancer Res. (2005) 11:7800-6. doi: 10.1158/1078-0432.CCR-05-1288

20. Goey AK, Meijerman I, Rosing H, Marchetti S, Mergui-Roelvink M, Keessen $\mathrm{M}$, et al. The effect of St John's wort on the pharmacokinetics of docetaxel. Clin Pharmacokinet. (2014) 53:103-10. doi: 10.1007/s40262-013-0102-5

21. Mathijssen RH, Verweij J, de Bruijn P, Loos WJ, Sparreboom A. Effects of St. John's wort on irinotecan metabolism. J Nat Cancer Inst. (2002) 94:1247-9. doi: 10.1093/jnci/94.16.1247

22. Smith P, Bullock JM, Booker BM, Haas CE, Berenson CS, Jusko WJ. The influence of St. John's wort on the pharmacokinetics and protein binding of imatinib mesylate. Pharmacotherapy. (2004) 24:1508-14. doi: 10.1592/phco.24.16.1508.50958

23. Frye RF, Fitzgerald SM, Lagattuta TF, Hruska MW, Egorin MJ. Effect of St John's wort on imatinib mesylate pharmacokinetics. Clin Pharmacol Ther. (2004) 76:323-9. doi: 10.1016/j.clpt.2004.06.007

24. Fasinu P, Bouic P, Rosenkranz B. An overview of the evidence and mechanisms of herb-drug interactions. Front Pharmacol. (2012) 3:69. doi: 10.3389/fphar.2012.00069

25. Izzo AA. Herb-drug interactions: an overview of the clinical evidence. Fund Clin Pharmacol. (2005) 19:1-6. doi: 10.1111/j.1472-8206.2004.00301.x

26. Sheweita SA, Newairy AA, Mansour HA, Yousef MI. Effect of some hypoglycemic herbs on the activity of phase I and II drug-metabolizing enzymes in alloxan-induced diabetic rats. Toxicology. (2002) 174:131-9. doi: 10.1016/S0300-483X(02)00048-3

27. Iqbal M, Sharma SD, Okazaki Y, Fujisawa M, Okada S. Dietary supplementation of curcumin enhances antioxidant and phase II metabolizing enzymes in ddY male mice: possible role in protection against chemical carcinogenesis and toxicity. Pharmacol Toxicol. (2003) 92:33-8. doi: 10.1034/j.1600-0773.2003.920106.x

28. Mohamed ME, Frye RF. Inhibition of intestinal and hepatic glucuronidation of mycophenolic acid by Ginkgo biloba extract and flavonoids. Drug Metab Dispos. (2010) 38:270-5. doi: 10.1124/dmd.109.030080
29. Mohamed ME, Frye RF. Inhibitory effects of commonly used herbal extracts on UDP-glucuronosyltransferase 1A4, 1A6, and 1A9 enzyme activities. Drug Metab Dispos. (2011) 39:1522-8. doi: 10.1124/dmd.111.039602

30. Juliano RL, Ling V. A surface glycoprotein modulating drug permeability in Chinese hamster ovary cell mutants. Biochim Biophys Acta. (1976) 455:15262. doi: 10.1016/0005-2736(76)90160-7

31. Zhang S, Morris ME. Effects of the flavonoids biochanin A, morin, phloretin, and silymarin on P-glycoprotein-mediated transport. J Pharmacol Exp Ther. (2003) 304:1258-67. doi: 10.1124/jpet.102.044412

32. Choi CH, Kang G, Min YD. Reversal of P-glycoprotein-mediated multidrug resistance by protopanaxatriol ginsenosides from Korean red ginseng. Planta Med. (2003) 69:235-40. doi: 10.1055/s-2003-38483

33. Bhardwaj RK, Glaeser H, Becquemont L, Klotz U, Gupta SK, Fromm MF. Piperine, a major constituent of black pepper, inhibits human Pglycoprotein and CYP3A4. J Pharmacol Exp Ther. (2002) 302:645-50. doi: $10.1124 /$ jpet.102.034728

34. Nabekura T, Kamiyama S, Kitagawa S. Effects of dietary chemopreventive phytochemicals on P-glycoprotein function. Biochem Biophys Res Commun. (2005) 327:866-70. doi: 10.1016/j.bbrc.2004.12.081

35. Block KI, Mead MN. Immune system effects of echinacea, ginseng, and astragalus: a review. Integr Cancer Therapies. (2003) 2:247-67. doi: $10.1177 / 1534735403256419$

36. Sultan MT, Buttxs MS, Qayyum MM, Suleria HA. Immunity: plants as effective mediators. Crit Rev Food Sci Nutr. (2014) 54:1298-308. doi: 10.1080/10408398.2011.633249

37. Miller SC. Echinacea: a miracle herb against aging and cancer? Evidence in vivo in mice. Evid Based Complement Alternat Med. (2005) 2:309-14. doi: $10.1093 /$ ecam/neh118

38. Binns CW, Lee MK, Lee AH. Problems and prospects: public health regulation of dietary supplements. Annu Rev Public Health. (2018) 39:403-20. doi: 10.1146/annurev-publhealth-040617-013638.

39. Awortwe C, Manda VK, Avonto C, Khan SI, Khan IA, Walker LA, et al. Echinacea purpurea up-regulates CYP1A2, CYP3A4 and MDR1 gene expression by activation of pregnane $\mathrm{X}$ receptor pathway. Xenobiotica. (2015) 45:218-29. doi: 10.3109/00498254.2014.973930

40. Hansen TS, Nilsen OG. In vitro CYP3A4 metabolism: inhibition by Echinacea purpurea and choice of substrate for the evaluation of herbal inhibition. Basic Clin Pharmacol Toxicol. (2008) 103:445-9. doi: $10.1111 /$ j.1742-7843.2008.00307.x

41. Gorski JC, Huang SM, Pinto A, Hamman MA, Hilligoss JK, Zaheer $\mathrm{NA}$, et al. The effect of echinacea (Echinacea purpurea root) on cytochrome P450 activity in vivo. Clin Pharmacol Ther. (2004) 75:89-100. doi: 10.1016/j.clpt.2003.09.013

42. Moltó J, Valle M, Miranda C, Cedeño S, Negredo E, Barbanoj MJ, et al. Herb-drug interaction between Echinacea purpurea and darunavir-ritonavir in HIV-infected patients. Antimicrob Agents Chemother. (2011) 55:326-30. doi: 10.1128/AAC.01082-10

43. Ernst E, Pittler MH, Wider B. The Desktop Guide to Complementary and Alternative Medicine. Philadelphia, PA: Mosby Elsevier (2006).

44. Foster BC, Gallicano K, Cameron W, Choudhri SH. Constituents of garlic inhibit cytochrome P450 3A4-mediated drug metabolism. Can J Infect Dis. (1998) 9(Suppl A):472P.

45. Gillis CN. Panax ginseng pharmacology: a nitric oxide link? Biochem Pharmacol. (1997) 54: 1-8. doi: 10.1016/S0006-2952(97)00193-7

46. Chen X. Cardiovascular protection by ginsenosides and their nitric oxide releasing action. Clin Exp Pharmacol Physiol. (1996) 23:728-32. doi: 10.1111/j.1440-1681.1996.tb01767.x

47. Yun YS, Moon HS, Oh YR, Jo SK, Kim YJ, Yun TK. Effect of red ginseng on natural killer cell activity in mice with lung adenoma induced by urethan and benzo(a)pyrene. Cancer Detection Prev Suppl. (1987) 1:301-9.

48. Yuan CS, Attele AS, Wu JA, Liu D. Modulation of American ginseng on brainstem GABAergic effects in the rat. J Ethnopharmacol. (1998) 63:215-22. doi: 10.1016/S0378-8741(98)00066-X

49. Zhu JH, Takeshita T, Kitagawa I, Morimoto K. Suppression of the formation of sister chromatid exchanges by low concentrations of ginsenoside $\mathrm{Rh} 2$ in human blood lymphocytes Cancer Res. (1995) 55:1221-3.

50. Zheng YF, Bae SH, Choi EJ, Park JB, Kim SO, Jang MJ, et al. Evaluation of the in vitro/in vivo drug interaction potential of BST204, a purified dry 
extract of ginseng, and its four bioactive ginsenosides through cytochrome P450 inhibition/induction and UDP-glucuronosyltransferase inhibition. Food Chem Toxicol. (2014) 68:117-27. doi: 10.1016/j.fct.2014.03.004

51. Liu KH, Kim MJ, Jeon BH, Shon JH, Cha IJ, Cho KH, et al. Inhibition of human cytochrome P450 isoforms and NADPH-CYP reductase in vitro by 15 herbal medicines, including Epimedii herba. J Clin Pharm Ther. (2006) 31:83-91. doi: 10.1111/j.1365-2710.2006.00706.x

52. Henderson GL, Harkey MR, Gershwin ME, Hackman RM, Stern JS, Stresser DM. Effects of ginseng components on c-DNA-expressed cytochrome P450 enzyme catalytic activity. Life Sci. (1999) 65:PL209-14. doi: 10.1016/S0024-3205(99)00407-5

53. Gum SI, Jo SJ, Ahn SH, Kim SG, Kim JT, Shin HM, et al. The potent protective effect of wild ginseng (Panax ginseng CA Meyer) against benzo $[\alpha]$ pyrene-induced toxicity through metabolic regulation of CYP1A1 and GSTs. J Ethnopharmacol. (2007) 112:568-76. doi: 10.1016/j.jep.2007.05.014

54. Kim HJ, Chun YJ, Park JD, Kim SI, Roh JK, Jeong TC. Protection of rat liver microsomes against carbon tetrachloride-induced lipid peroxidation by red ginseng saponin through cytochrome P450 inhibition. Planta Medica. (1997) 63:415-8. doi: 10.1055/s-2006-957724

55. Malati CY, Robertson SM, Hunt JD, Chairez C, Alfaro RM, Kovacs JA, et al. Influence of Panax ginseng on Cytochrome P450 (CYP) 3A and Pglycoprotein (P-gp) activity in healthy participants. J Clin Pharmacol. (2012) 52:932-9. doi: 10.1177/0091270011407194

56. Dahan A, Altman H. Food-drug interaction: grapefruit juice augments drug bioavailability-mechanism, extent and relevance. Eur J Clin Nutr. (2004) 58:1. doi: 10.1038/sj.ejen.1601736

57. Chen M, Zhou SY, Fabriaga E, Zhang PH, Zhou Q. Food-drug interactions precipitated by fruit juices other than grapefruit juice: an update review. J Food Drug Anal. (2018) 26:S61-71. doi: 10.1016/j.jfda.2018.01.009

58. Kroll DJ, Shaw HS, Oberlies NH. Milk thistle nomenclature: why it matters in cancer research and pharmacokinetic studies. Integr Cancer Ther. (2007) 6:110-9. doi: 10.1177/1534735407301825

59. Schroder FH, Roobol MJ, Boeve ER, de Mutsert R, Zuijdgeest-van Leeuwen SD, Kersten I, et al. Randomized, double-blind, placebo-controlled crossover study in men with prostate cancer and rising PSA: effectiveness of a dietary supplement. Eur Urol. (2005) 48:922-30. doi: 10.1016/j.eururo.2005.08.005

60. Hoh C, Boocock D, Marczylo T, Singh R, Berry DP, Dennison AR, et al. Pilot study of oral silibinin, a putative chemopreventive agent, in colorectal cancer patients: silibinin levels in plasma, colorectum, and liver and their pharmacodynamic consequences. Clin Cancer Res. (2006) 12:2944-50. doi: 10.1158/1078-0432.CCR-05-2724

61. Brantley SJ, Oberlies NH, Kroll DJ, Paine MF. Two flavonolignans from milk thistle (Silybum marianum) inhibit CYP2C9-mediated warfarin metabolism at clinically achievable concentrations. J Pharmacol Exp Ther. (2010) 332:1081-7. doi: 10.1124/jpet.109.161927

62. Venkataramanan R, Ramachandran V, Komoroski BJ, Zhang S, Schiff PL, Strom SC. Milk thistle, a herbal supplement, decreases the activity of CYP3A4 and uridine diphosphoglucuronosyl transferase in human hepatocyte cultures. Drug Metab Dispos. (2000) 28:1270-3.

63. Han Y, Guo D, Chen Y, Chen Y, Tan ZR, Zhou HH. Effect of silymarin on the pharmacokinetics of losartan and its active metabolite E-3174 in healthy Chinese volunteers. Eur J Clin Pharmacol. (2009) 65:585-91. doi: 10.1007/s00228-009-0624-9

64. Wen Z, Dumas TE, Schrieber SJ. Pharmacokinetics and metabolic profile of free, conjugated, and total silymarin flavonolignans in human plasma after oral administration of milk thistle extract. Drug Metab Dispos. (2008) 36:65-72. doi: 10.1124/dmd.107.017566

65. Linde K, Ramirez G, Mulrow CD, Pauls A, Weidenhammer W, Melchart D. St John's wort for depression-an overview and meta-analysis of randomised clinical trials. BMJ. (1996) 313:253-8. doi: 10.1136/bmj.313.7052.253

66. Williams JW Jr, Mulrow CD, Chiquette E, Noël PH, Aguilar C, Cornell J, et al. A systematic review of newer pharmacotherapies for depression in adults: evidence report summary. Ann Intern Med. (2000) 132:743-56. doi: 10.7326/0003-4819-132-9-200005020-00011

67. Stevinson C, Ernst E. A pilot study of Hypericum perforatum for the treatment of premenstrual syndrome. Br J Obstet Gynaecol. (2000) 107:870-6. doi: 10.1111/j.1471-0528.2000.tb11085.x
68. Winkel R, Koritsch HD, Piayda H. St John's wort extract LI 160 in depressive, alcohol-addicted patients [abstract]. Phytomedicine. (2000) 7(Suppl 2):19.

69. Müller T, Mannel M, Murck H, Rahlfs VW. Treatment of somatoform disorders with St John's wort: a randomized, double-blind and placebo-controlled trial. Psychosom Med. (2004) 66: 538-47. doi: 10.1097/01.psy.0000128900.13711.5b

70. Volz HP, Murck H, Kasper S, Möller HJ. St John's wort extract (LI 160) in somatoform disorders: results of a placebo-controlled trial. Psychopharmacology. (2002) 164:294-300. doi: 10.1007/s00213-002-1171-6

71. Greeson JM, Sanford B, Monti DA. St John's wort (Hypericum perforatum): a review of the current pharmacological, toxicological, and clinical literature. Psychopharmacology. (2001) 153:402-14. doi: 10.1007/s002130 000625

72. Obach RS. Inhibition of human cytochrome P450 enzymes by constituents of St John's Wort, an herbal preparation used in the treatment of depression. $J$ Pharmacol Exp Ther. (2000) 294:88-95.

73. Wang LS, Zhou G, Zhu B, Wu J, Wang JG, Abd El-Aty AM, et al. St John's wort induces both cytochrome P450 3A4-catalyzed sulfoxidation and 2C19-dependent hydroxylation of omeprazole. Clin Pharmacol Ther. (2004) 75:191-7. doi: 10.1016/j.clpt.2003.09.014

74. Sugimoto K, Ohmori M, Tsuruoka S, Nishiki K, Kawaguchi A, Harada $\mathrm{K}$, et al. Different effects of St John's wort on the pharmacokinetics of simvastatin and pravastatin. Clin Pharmacol Ther. (2001) 70:518-24. doi: 10.1016/S0009-9236(01)64092-X

75. Bauer S, Stormer E, Johne A, Krüger H, Budde K, Neumayer HH, et al. Alterations in cyclosporine A pharmacokinetics and metabolism during treatment with St John's wort in renal transplant patients. Br J Clin Pharmacol. (2003) 55:203-11. doi: 10.1046/j.1365-2125.2003. 01759.x

76. Piscitelli SC, Burstein AH, Chaitt D, Alfaro RM, Falloon J. Indinavir concentrations and St John's wort. Lancet. (2000) 355:547-8. doi: 10.1016/S0140-6736(99)05712-8

77. Tannergren C, Engman H, Knutson L, Hedeland M, Bondesson U, Lennernäs $\mathrm{H}$, et al. St John's wort decreases the bioavailability of R- and S-verapamil through induction of the first-pass metabolism. Clin Pharmacol Ther. (2004) 75:298-309. doi: 10.1016/S0009-9236(03)00773-2

78. Mai I, Stormer E, Bauer S, Krüger H, Budde K, Roots I. Impact of St John's wort treatment on the pharmacokinetics of tacrolimus and mycophenolic acid in renal transplant patients. Nephrol Dial Transplant. (2003) 18:819-22. doi: $10.1093 / \mathrm{ndt} / \mathrm{gfg} 002$

79. Hu ZP, Yang XX, Chan SY, Xu AL, Duan W, Zhu YZ, et al. St. John's wort attenuates irinotecan-induced diarrhea via down-regulation of intestinal pro-inflammatory cytokines and inhibition of intestinal epithelial apoptosis. Toxicol Appl Pharmacol. (2006) 216:225-37. doi: 10.1016/j.taap. 2006.05.020

80. Henderson JW, Donatelle RJ. Complementary and alternative medicine use by women after completion of allopathic treatment for breast cancer. Altern Ther Health Med. (2004) 10:52-7.

81. Zeller T, Muenstedt K, Stoll C, Schweder J, Senf B, Ruckhaeberle E, et al. Potential interactions of complementary and alternative medicine with cancer therapy in outpatients with gynecological cancer in a comprehensive cancer center. J Cancer Res Clin Oncol. (2013) 139:357-65. doi: 10.1007/s00432-012-1336-6

82. Alsanad SM, Williamson EM, Howard RL. Cancer patients at risk of herb/food supplement-drug interactions: a systematic review. Phytother Res. (2014) 28:1749-55. doi: 10.1002/ptr.5213

Conflict of Interest: The authors declare that the research was conducted in the absence of any commercial or financial relationships that could be construed as a potential conflict of interest.

Copyright (๑) 2019 Fasinu and Rapp. This is an open-access article distributed under the terms of the Creative Commons Attribution License (CC BY). The use, distribution or reproduction in other forums is permitted, provided the original author(s) and the copyright owner(s) are credited and that the original publication in this journal is cited, in accordance with accepted academic practice. No use, distribution or reproduction is permitted which does not comply with these terms. 